\title{
Determinação de Níveis de Metionina+Cistina para Poedeiras Semi-pesadas Alimenta- das com Rações contendo Levedura Seca (Saccharomyces cerevisiae) ${ }^{1}$
}

\author{
Cristina Kimie Togashi², José Brandão Fonseca ${ }^{3}$, Rita da Trindade Ribeiro Nobre Soares ${ }^{4}$, \\ Cláudio Luiz Melo de Souza ${ }^{5}$
}

\begin{abstract}
RESUMO - Um experimento foi realizado utilizando-se 120 galinhas poedeiras de ovos marrons, da linhagem comercial Isa Brown, alimentadas com rações contendo levedura de cana-de-açúcar, visando à determinação das exigências nutricionais de metionina+cistina (met+cis). As aves possuíam 51 semanas de idade ao início do experimento, que teve a duração de 84 dias, com três períodos de 28 dias cada. O delineamento experimental utilizado foi o de blocos casualizados com cinco tratamentos e quatro repetições. Os tratamentos consistiram de uma ração basal, suplementada com cinco níveis de DL-metionina, a fim de se obterem rações com 0,$45 ; 0,50 ; 0,55 ; 0,60$ e $0,65 \%$ de met+cis. A ração basal isoprotéica $(13 \% \mathrm{~PB})$ e isocalórica $(2840 \mathrm{kcal} \mathrm{EM} / \mathrm{kg})$ era composta por milho moído, farelo de soja e levedura de cana-de-açúcar. Foram analisadas variáveis referentes ao desempenho produtivo (produção de ovos, ganho de peso, consumo e conversão alimentar) e qualidade dos ovos (peso, massa e conteúdo de ovos e Unidades Haugh). Foi observado um efeito quadrático dos níveis de met+cis sobre as características avaliadas, com exceção do ganho de peso, que não sofreu influência dos tratamentos. Utilizando-se modelos de regressão, foi possível a determinação dos melhores níveis de met+cis a serem utilizados. Para a maximização da produção de ovos e consumo de ração, as exigências foram estimadas em 0,565 e $0,569 \%$ de met+cis, respectivamente. Para peso e massa de ovos, utilizando-se $0,582 \%$ e $0,569 \%$ de met + cis, foram obtidos os melhores resultados, respectivamente.
\end{abstract}

Palavras-chave: níveis, desempenho produtivo, galinhas poedeiras, qualidade do ovo, metionina+cistina

\section{Requirements of Methionine+Cystine by Brown Egg Layer Hens Fed Diets with Dry Yeast (Saccharomyces cerevisiae)}

\begin{abstract}
One experiment was carried out using 120 laying Isa Brown chickens fed diets containing sugar-cane yeast, to determinate the methionine+cystine (met+cys) requirements. The birds were 51 weeks old at the beginning of the experiment, with the duration of 84 days, with three periods of 28 days each. A completely randomized block design with five treatments and four replications was used. The treatments consisted of a basal diet supplemented with five levels of DL-methionine in order to obtain diets with 0.45 , $0.50,0.55,0.60$, and $0.65 \%$ of met + cys. The basal diet with $13 \% \mathrm{CP}$ and $2840 \mathrm{kcal} \mathrm{EM} / \mathrm{kg}$ was composed by corn, soy bean meal and sugar-cane yeast. Referring variables were analyzed to the productive performance (production of eggs, weight gain, feed consumption and conversion) and quality of the eggs (weigh, mass and content of eggs and Haugh Units). A quadratic effect of the met + cys levels was observed on the appraised characteristics, except for the weight gain that was not influenced by the treatments. Working with regression models, it was possible the determination of the best met+cys levels. For greater egg production and ration consumption, the requirements were .565 and $.569 \%$ of met + cys, respectively. For egg weight and egg mass the use of $.582 \%$ and $.569 \%$ of met + cys, allowed to obtain the better results, respectively.
\end{abstract}

Key Words: requirement, productive performance, laying hens, quality of egg and methionine+cystine

\section{Introdução}

O avanço tecnológico obtido nas últimas décadas favoreceu o desenvolvimento da avicultura brasileira, destacando-se o Brasil como o segundo produtor mundial de carne de frango. A produção brasileira de frangos que em 1970, foi de 217 mil toneladas, passou para mais de 5,1 milhões de toneladas em 1999, segundo estimativas de Filho et al. (2000). O crescimento demográfico tem contribuído para o aumento na demanda por alimentos, principalmente os de origem animal, como importante fonte protéica na alimentação humana.

A alimentação representa cerca de 60 a $70 \%$ dos custos de produção e é, normalmente, considerada o item de maior custo da produção animal. A maior eficiência de utilização da proteína dietética pelas aves irá proporcionar

\footnotetext{
1 Parte do trabalho de tese do primeiro autor, projeto financiado pela FENORTE e pela FAPERJ.

2 Doutoranda em Produção Animal. UENF/CCTA/LZNA. Av. Alberto Lamego, 2000-Campos/RJ 28015-620. E.mail:cktogashi@yahoo.com.br

3 Professor do Laboratório de Zootecnia e Nutrição Animal da UENF. Av. Alberto Lamego, 2000 - Campos/RJ - $28015-620$.

E.mail: cppg@uenf.br

${ }^{4}$ Professora do Laboratório de Zootecnia e Nutrição Animal da UENF. E.mail: rnobre@uenf.br

5 Diretor do Instituto Superior de Tecnologia e Ciências Agrárias - FAETEC. E.mail: claudiomelo@escola24horas.com.br
} 
o suprimento adequado de suas exigências nutricionais de aminoácidos, diminuindo os efeitos de poluição ambiental pela redução da excreção de nitrogênio, além de propiciar a redução dos custos de produção. A utilização de aminoácidos sintéticos tem permitido a adequação das rações às exigências nutricionais das aves. A metionina é considerada o primeiro aminoácido limitante para aves e sua forma sintética vem sendo utilizada comumente nas formulações de rações para frangos de corte à base de milho e farelo de soja.

A competição gerada pela utilização de cereais e suplementos protéicos vegetais, tanto em humanos como em animais, o aproveitamento de subprodutos da indústria que normalmente são impróprios para alimentação humana e o desenvolvimento da avicultura em regiões com baixa disponibilidade de grãos, tem despertado o interesse pelo uso de alimentos denominados "não-convencionais" ou "alternativos". A levedura é um subproduto do processamento da cana-de-açúcar, amplamente estudado e utilizado na alimentação animal, como fonte protéica e de outros nutrientes (Pepler, 1970; Miyada \& Lavorenti, 1979; Lima et al., 1988; Panobianco et al., 1989; Landel Filho et al., 1994; Botelho et al., 1998).

O objetivo deste trabalho foi determinar o melhor nível de metionina+cistina para poedeiras de ovos marrons, alimentadas com rações à base de milho e farelo de soja, contendo levedura proveniente de usina de cana-de-açúcar.

\section{Material e Métodos}

O experimento foi conduzido no setor de Avicultura do Laboratório de Zootecnia e Nutrição Animal do CCTA/UENF, no município de Campos dos Goytacazes, Rio de Janeiro.

Foram utilizadas 120 galinhas da linhagem comercial Isa Brown, com 51 semanas de idade ao início do experimento, que teve a duração de 84 dias, com três períodos de 28 dias cada.

As aves foram alojadas em um galpão de alvenaria com $30 \mathrm{~m}$ de comprimento, $10 \mathrm{~m}$ de largura e 2,80 $\mathrm{m}$ de pé-direito, cercado por telas e coberto por telhas de amianto e lanternim. A área destinada ao experimento era composta por três conjuntos de gaiolas de arame galvanizado, separados por dois corredores. Cada gaiola era composta por seis compartimentos de $25 \times 40 \times 40 \mathrm{~cm}$, cada um provido de um comedouro individual e bebedouro tipo calha. Apenas uma ave foi alojada em cada compartimento, totalizando seis aves por unidade experimental. As temperaturas médias, máxima e mínima foram registradas durante todo o período experimental, através de um termômetro de máxima e mínima (Tabela 1).

Os tratamentos consistiram de uma ração basal isoprotéica (13\% PB) e isocalórica $(2840 \mathrm{kcal} / \mathrm{EM} / \mathrm{kg})$ contendo milho, farelo de soja e levedura, suplementada com DL-Metionina 99\% para que fossem obtidas rações com: 0,$45 ; 0,50 ; 0,55 ; 0,60$ e $0,65 \%$ de met + cis. As rações experimentais (Tabela 2) foram formuladas de modo a satisfazer às exigências nutricionais das aves de acordo com recomendações de Rostagno et al. (1994).

A levedura seca de cana-de-açúcar foi adicionada à ração basal no nível de $6 \%$, de acordo com resultados obtidos em outros experimentos (Panobianco et al., 1989 e Botelho et al., 1998). A levedura utilizada foi da safra de 1998, de partida única, proveniente de uma usina de cana-de-açúcar localizada nas proximidades da região onde $o$ experimento foi realizado.

As rações experimentais foram fornecidas diariamente pela manhã, garantindo às aves o consumo de ração à vontade durante todo o período experimental. A água foi fornecida também à vontade, em bebedouros tipo calha de tubos de PVC, localizados acima dos comedouros nas gaiolas.

As aves foram manejadas durante as fases de cria e recria de acordo com as recomendações propostas pelo Guía de Manejo Ponedoras Isabrown- ISA (1993). Antes do início do experimento, as aves foram distribuídas nas gaiolas de acordo com o peso corporal e a produção de ovos, previamente observados, de forma a se obter uma padronização dos animais, por unidade experimental.

As variáveis analisadas referentes às características de desempenho produtivo dos animais foram: produção de ovos, ganho de peso, peso médio e massa de ovos, consumo de ração e conversão alimentar; as da qualidade do ovo foram o conteúdo de ovo, o peso

Tabela 1 - Temperaturas mínima e máxima médias, observadas durante o período experimental

Table 1 - Temperature during the experimental period

\begin{tabular}{lcc}
\hline $\begin{array}{l}\text { Período } \\
\text { Period }\end{array}$ & \multicolumn{2}{c}{$\begin{array}{c}\text { Temperatura }\left({ }^{\circ} \mathrm{C}\right) \\
\text { Temperature }\end{array}$} \\
\hline & Mínima & Máxima \\
& Minimum & Maximum \\
\hline I & 22,20 & 33,18 \\
II & 20,01 & 28,77 \\
III & 17,57 & 28,40 \\
\hline
\end{tabular}


Tabela 2 - Composição percentual das rações experimentais

Table 2 - Percentage composition of experimental diets

\begin{tabular}{|c|c|c|c|c|c|}
\hline \multirow[t]{2}{*}{$\begin{array}{l}\text { Ingredientes } \\
\text { Ingredients }(\%)\end{array}$} & \multicolumn{5}{|c|}{$\begin{array}{c}\text { Níveis de metionina }+ \text { cistina }(\text { met }+ \text { cis }) \text { nas rações }(\%) \\
\text { Methione }+ \text { cystine }(\text { met }+ \text { cys) levels on diets }(\%)\end{array}$} \\
\hline & 0,45 & 0,50 & 0,55 & 0,60 & 0,65 \\
\hline Milho & 70,97 & 70,91 & 70,86 & 70,80 & 70,75 \\
\hline Corn & & & & & \\
\hline Farelo de soja & 10,40 & 10,41 & 10,41 & 10,42 & 10,42 \\
\hline Soy bean meal & & & & & \\
\hline Levedura & 6,00 & 6,00 & 6,00 & 6,00 & 6,00 \\
\hline $\begin{array}{l}\text { Yeast } \\
\text { DL-Met } 99\end{array}$ & 0,01 & 0,06 & 0,11 & 0,16 & 0,21 \\
\hline $\begin{array}{l}\text { Methionine } \\
\text { Fosfato bicálcico }\end{array}$ & & & & & \\
\hline Dicalcium phosphate & 1,13 & 1,13 & 1,13 & 1,13 & 1,13 \\
\hline Calcário & 8,34 & 8,34 & 8,34 & 8,34 & 8,34 \\
\hline Limestone & & & & & \\
\hline $\begin{array}{l}\text { Sal iodado } \\
\text { Iodate salt }\end{array}$ & 0,30 & 0,30 & 0,30 & 0,30 & 0,30 \\
\hline Suplemento vitamínico ${ }^{1}$ & 0,20 & 0,20 & 0,20 & 0,20 & 0,20 \\
\hline $\begin{array}{l}\text { Vitamine mix } \\
\text { Supl.mineral }\end{array}$ & 0,15 & 0,15 & 0,15 & 0,15 & 0,15 \\
\hline Mineral mix & & & & & \\
\hline $\begin{array}{l}\text { Inerte } \\
\text { Inert }\end{array}$ & 2,50 & 2,50 & 2,50 & 2,50 & 2,50 \\
\hline Total & 100,00 & 100,00 & 100,00 & 100,00 & 100,00 \\
\hline EM (kcal/kg) & 2838,00 & 2839,00 & 2839,00 & 2840,00 & 2841,00 \\
\hline$M E$ & & & & & \\
\hline Proteína bruta & 13,00 & 13,03 & 13,06 & 13,08 & 13,11 \\
\hline Crude protein & & & & & \\
\hline $\begin{array}{l}\text { Gordura } \\
\text { Fat }\end{array}$ & 2,44 & 2,44 & 2,44 & 2,43 & 2,43 \\
\hline $\begin{array}{l}\text { Fósforo total } \\
\text { Total phosphorus }\end{array}$ & 0,50 & 0,50 & 0,50 & 0,50 & 0,50 \\
\hline $\begin{array}{l}\text { Fósforo disponível } \\
\text { Available phosphorus }\end{array}$ & 0,32 & 0,32 & 0,32 & 0,32 & 0,32 \\
\hline $\begin{array}{l}\text { Cálcio } \\
\text { Calcium }\end{array}$ & 3,50 & 3,50 & 3,50 & 3,50 & 3,50 \\
\hline Sódio & 0,15 & 0,15 & 0,15 & 0,15 & 0,15 \\
\hline Sodium & & & & & \\
\hline $\begin{array}{l}\text { Met }+ \text { Cis } \\
\text { Met }+ \text { Cys }\end{array}$ & 0,45 & 0,50 & 0,55 & 0,60 & 0,65 \\
\hline Metionina & 0,23 & 0,28 & 0,33 & 0,34 & 0,43 \\
\hline Methionine & & & & & \\
\hline Lisina & 0,60 & 0,60 & 0,60 & 0,60 & 0,60 \\
\hline Lysine & & & & & \\
\hline Treonina & 0,52 & 0,52 & 0,52 & 0,52 & 0,52 \\
\hline
\end{tabular}

1 Puramix Vita Postura 0,2\% (Ralston Purina do Brasil Ltda.) Composição/kg: Vit. A 4.840 .000 U.l. Vit. D3, 1.237 .500 U.l; Vit. E, 2.750 U.I; Vit. K, 180 mg; Vit. B2, 3.135mg; Vit. B12, 6.875 mcg; Ác. Pantotênico, 3.850 mg; Niacina, 12.100 mg; Ác. Fólico, 110 mg; Antioxidante, $200 \mathrm{mg}$; Veículo q.s.p, $1000 \mathrm{~g}$

${ }^{2}$ Puramix Mineral Postura 0,15\% (Ralston Purina do Brasil Ltda.)Composição química/kg: Cobre, 14.520 mg; lodo, 990 mg; Manganês, $50.000 \mathrm{mg}$; Selênio, $110 \mathrm{mg}$; Zinco, $43.890 \mathrm{mg}$; Veículo q.s.p.,1000 g 
de casca por superfície de área, a gravidade específica e Unidades Haugh.

A massa de ovos foi obtida através do produto do número de ovos produzidos em cada período pelo peso médio dos ovos. O valor do conteúdo de ovos foi obtido pelo produto do número de ovos postos pelo peso médio dos mesmos, subtraído do peso da casca. O peso de casca por superfície de área (PCSA) foi determinado segundo Abdallah et al. (1993) pela fórmula: $\mathrm{PCSA}=[\mathrm{PC} /(3,9782 \times \mathrm{Po} 0,7056)] \times 1000$, em que: $\mathrm{PC}=$ peso de casca e $\mathrm{Po}=$ peso do ovo.

A coleta dos ovos foi realizada duas vezes ao dia, uma pela manhã e outra à tarde, quando eram feitas as anotações da produção. O ganho de peso foi obtido através da pesagem inicial e final das aves no experimento. O consumo alimentar foi observado através da diferença obtida entre a quantidade de ração fornecida e as sobras obtidas. A conversão alimentar foi expressa em quilo de ração por dúzia de ovos produzidos e em gramas de ração por grama de ovos produzidos.

Com relação às avaliações da qualidade dos ovos, estas foram realizadas dois dias antes do fim de cada período (aos 26 dias), quando quatro ovos de cada unidade experimental foram amostrados e identificados com o número de cada tratamento e repetição, para que fossem utilizados nas pesagens dos ovos e das cascas e na determinação da gravidade específica, por intermédio do método de flutuação salina, descrito por Moreng \& Avens (1990).

Os ovos amostrados foram posteriormente quebrados, visando à medição da altura do albúmen para a determinação das Unidades Haugh, por meio de uma relação logarítmica entre o peso do ovo e a altura do albúmen, segundo a fórmula proposta por Haugh (1937): $\mathrm{UH}=100 \log (\mathrm{H}+7,5-1,7 \mathrm{~W}$ 0,37); em que: $\mathrm{H}=$ altura do albúmen $(\mathrm{mm})$ e $\mathrm{W}=$ peso do ovo $(\mathrm{g})$.
O delineamento experimental utilizado para a determinação do melhor nível de metionina+cistina a ser fornecido a galinhas poedeiras de ovos marrons foi o de blocos ao acaso, em esquema de parcela subdividida, composto por cinco tratamentos nas parcelas e três períodos nas subparcelas. Para a formação dos blocos foram consideradas a localização das gaiolas no galpão e a unidade experimental composta por seis aves. Os dados obtidos foram submetidos à Análise de Variância (ANOVA) parcela subdividida do programa SAEG, desenvolvido pela Universidade Federal de Viçosa (1997).

As exigências nutricionais de metionina + cistina foram estimadas através da utilização de modelos de regressão polinomial, quando os efeitos foram significativos. Foram realizadas correlações entre todas as variáveis, utilizando-se a Correlação de Pearson.

\section{Resultados e Discussão}

Os dados foram analisados considerando-se os efeitos de períodos e tratamentos. Para as variáveis referentes ao desempenho produtivo, com exceção do ganho de peso, foram observadas diferenças significativas $(\mathrm{P}<0,05)$ entre os períodos estudados, conforme é apresentado na Tabela 3.

A produção de ovos apresentou aumentos significativos $(\mathrm{P}<0,05)$ com o aumento da idade das poedeiras. No entanto, os valores obtidos estão condizentes com Waldroup \& Hellwig (1995) e pelo Guia de Manejo Ponedoras Isabrown ISA (1993).

$\mathrm{O}$ aumento das exigências nutricionais, visando a atender à maior produção de ovos, pode ter ocasionado o maior consumo de alimentos, assim como a adaptação das aves aos tratamentos, considerando-se que não houve período prévio de adaptação e efeito de

Tabela 3 - Valores médios de produção de ovos (PO), massa de ovo(MO), consumo de ração (CR) e conversão alimentar (CA) das poedeiras durante o período experimental

Table 3 - Mean values of egg production (EP),egg mass (EM), feed intake (FI) and feed: egg ratio (FCR)

\begin{tabular}{|c|c|c|c|c|c|}
\hline $\begin{array}{l}\text { Período } \\
\text { Period }\end{array}$ & $\begin{array}{c}\mathrm{PO}(\%) \\
E P\end{array}$ & $\begin{array}{c}\mathrm{MO}(\mathrm{g}) \\
E M\end{array}$ & $\begin{array}{c}\text { CR } \\
\text { FI } \\
\text { (g/ave/dia) } \\
\text { (g/bird/day) }\end{array}$ & $\begin{array}{c}\mathrm{CA} \\
F C R \\
(\mathrm{~kg} / \mathrm{dz}) \\
(\mathrm{kg} \text { feed } / \mathrm{dz} \text { egg) }\end{array}$ & $\begin{array}{c}\mathrm{CA} \\
F C R \\
(\mathrm{~g} / \mathrm{g}) \\
(\mathrm{g} \text { feed } / \mathrm{g} \text { egg) }\end{array}$ \\
\hline I & $66,43^{\mathrm{a}}$ & $42,45^{a}$ & $118,86^{\mathrm{a}}$ & $2,15^{\mathrm{a}}$ & $2,82^{\mathrm{a}}$ \\
\hline II & $73,03^{b}$ & $46,56^{\mathrm{b}}$ & $116,63^{a}$ & $1,93^{\mathrm{b}}$ & $2,55^{\mathrm{b}}$ \\
\hline III & $74,46^{\mathrm{b}}$ & $48,33^{\mathrm{b}}$ & $123,89^{b}$ & $2,00^{\mathrm{b}}$ & $2,58^{\mathrm{b}}$ \\
\hline $\mathrm{CV}(\%)$ & 6,92 & 8,20 & 4,12 & 6,46 & 7,61 \\
\hline
\end{tabular}

Médias seguidas de mesma letra nas colunas não diferem entre si, segundo Teste Tukey $(P \geq 0,05 ; n=20)$.

Means of same characteristics, followed by different letters in columns differ by Tukey test.

R. Bras. Zootec., v.31, n.3, p.1426-1433, 2002 (suplemento) 
interação entre os períodos e níveis de met+cis estudados.

Este maior consumo de alimentos influenciou nos valores de conversão alimentar, expressos tanto em $(\mathrm{kg} / \mathrm{dz})$ como em $(\mathrm{g} / \mathrm{g})$. Observa-se, na Tabela 3, que a conversão alimentar apresenta melhores resultados $(\mathrm{P}<0,05)$ ao final do período experimental, quando se presume o estabelecimento dos requerimentos nutricionais, assim como o conseqüente balanço energético e de aminoácidos das dietas.

Considerando-se o efeito de tratamentos sobre essas mesmas variáveis, e a não ocorrência de interação entre os períodos e tratamentos, observa-se, na Tabela 4, que todas as características apresentaram um efeito quadrático $(\mathrm{P}<0,05)$, isto é, à medida que os níveis de met+cis aumentavam nas rações, aumentavam-se os valores, até a obtenção de um valor máximo, a partir do qual ocorria posterior declínio dos valores.

Para a produção de ovos, observa-se que os menores valores são correspondentes aos menores níveis de met+cis nas rações. Estes resultados corroboram os obtidos por Harms \& Damron (1969); Narváez Solarte (1996); Barbosa (1997); e Harms et al.(1998). Segundo Harper et al. (1970); esta menor produção poderia ser explicada através do imbalanço de aminoácidos, decorrente da modificação na composição de aminoácidos da dieta, pela adição de aminoácidos em excesso. Através da derivação do modelo quadrático, a máxima produção de ovos foi obtida no nível de $0,565 \%$ de met + cis (Figura 1 ).

A elevação dos níveis de met + cis nas rações influenciou o peso dos ovos. Segundo Jensen et al. (1974), Waldroup \& Hellwig (1995) e Harms et al.

Tabela 4 - Efeito dos níveis de metionina+cistina (met+cis) sobre produção de ovos (PO), Peso de ovos (Po), massa de ovo(MO), consumo de ração (CR) e conversão alimentar (CA)

Table 4 - Effect of methionine+cystine (met+cys) on egg production (EP), egg weight (EW), egg mass (EM), feed intake (FI) and feed: egg ratio (FCR)

\begin{tabular}{|c|c|c|c|c|c|c|}
\hline $\begin{array}{l}\text { Níveis de met }+ \text { cis }(\%) \\
\text { Levels of met }+ \text { cys }\end{array}$ & $\begin{array}{c}\mathrm{PO}(\%) \\
E P\end{array}$ & $\begin{array}{l}\text { Po }(\mathrm{g}) \\
W E\end{array}$ & $\begin{array}{c}\mathrm{MO}(\mathrm{g}) \\
E M\end{array}$ & $\begin{array}{c}\text { CR } \\
F I \\
\text { (g/ave/dia) } \\
\text { (g/bird/day) }\end{array}$ & $\begin{array}{c}\mathrm{CA} \\
F C R \\
(\mathrm{~kg} / \mathrm{dz}) \\
(\mathrm{kg} \text { diet } / \mathrm{dz} \text { egg) }\end{array}$ & $\begin{array}{c}\mathrm{CA} \\
F C R \\
(\mathrm{~g} / \mathrm{g}) \\
\text { (g diet/gegg) }\end{array}$ \\
\hline$\overline{0,45}$ & 62,20 & $60,47^{\mathrm{a}}$ & 37,57 & 109,58 & 2,92 & 2,12 \\
\hline 0,50 & 72,92 & $63,97^{\mathrm{b}}$ & 46,65 & 119,65 & 2,58 & 1,98 \\
\hline 0,55 & 79,17 & $65,73^{\mathrm{b}}$ & 52,04 & 126,63 & 2,45 & 1,93 \\
\hline 0,60 & 71,43 & $65,50^{\mathrm{b}}$ & 46,77 & 122,69 & 2,64 & 2,08 \\
\hline 0,65 & 70,83 & $64,65^{\mathrm{b}}$ & 45,88 & 120,45 & 2,65 & 2,05 \\
\hline CV $(\%)$ & 6,92 & 2,98 & 8,20 & 4,12 & 7,61 & 6,46 \\
\hline
\end{tabular}

Efeito quadrático dos níveis de met+cis pelo teste $F(P<0,05)$. Quadratic effect of the met+cys levels $(P<.05)$ by test $F$.

(1998); existe alta relação entre o peso dos ovos e a produção de ovos sobre a qualidade da casca, que pode estar associada ao nível de met+cis na ração. A qualidade da casca dos ovos é alterada à medida que a produção de ovos aumenta, pois ocorre um aumento no peso dos ovos, sem que haja alteração na deposição da casca, ocasionando a formação de ovos com casca fina. Entretanto, neste trabalho, uma baixa correlação $(r=0,39)$ entre o peso e a produção de ovos foi observada.

Os menores níveis de suplementação de met + cis nas rações resultaram em ovos menos pesados e com cascas mais leves. Muitos trabalhos (Roland, 1980; Petersen et al., 1983; Jackson et al., 1987; Rodrigues et al., 1996) têm evidenciado a melhora na qualidade da casca dos ovos através da redução dos níveis de met+cis nas dietas; no

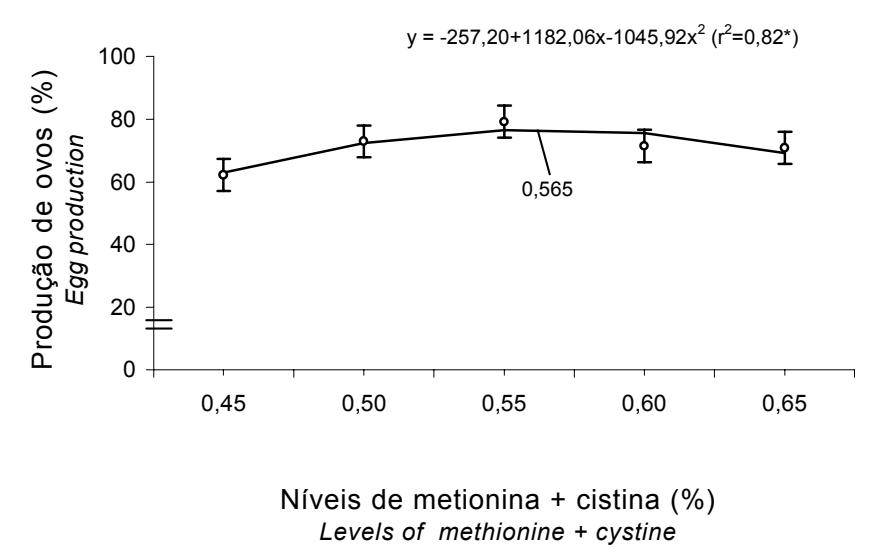

Figura 1 - Efeito dos níveis de metionina+cistina sobre a produção de ovos. * $(P<0,05)$.

Figure 1 - Effect of methionine+cystine levels on egg production. ${ }^{*}(P<.05)$. 
entanto, a taxa de produção de ovos é afetada, como pode ser observado neste trabalho.

De acordo com a derivação do modelo quadrático (Figura 2), a estimativa da exigência de met + cis para a maximização da variável peso do ovo foi de $0,582 \%$.

$\mathrm{O}$ consumo de ração também apresentou um efeito quadrático $(\mathrm{P}<0,05)$ em relação aos níveis de met + cis nas rações, como é demonstrado na Tabela 2. As variáveis consumo de ração e produção de ovos apresentaram comportamentos semelhantes com a elevação dos níveis de met+cis. Foi observada uma correlação positiva $(r=0,66)$ entre estas variáveis. Este maior consumo de alimentos pode ter ocorrido em virtude do aumento da energia necessária para elevar a produção de ovos. Os mesmos resultados foram observados por Harms \& Damron (1969); Sekiz et al. (1975); Rodrigues et al. (1996) e Harms et al. (1998).

Schutte et al. (1994) atribuíram a maior ingestão de alimentos à habilidade que as aves possuem de compensar a deficiência marginal de metionina, aumentando o consumo para atender ao seu requerimento. Entretanto, à medida que a deficiência se torna mais severa, a ingestão de alimentos diminui. Isto poderia explicar a ocorrência do efeito quadrático dos níveis de met + cis sobre o consumo de ração. Ao nível de $0,574 \%$ de met + cis alcançou-se o consumo máximo de ração (Figura 3).

A conversão alimentar, expressa em quilo de ração consumido por dúzia de ovos produzidos $(\mathrm{kg} / \mathrm{dz})$, não foi influenciada pelos diferentes níveis de met + cis

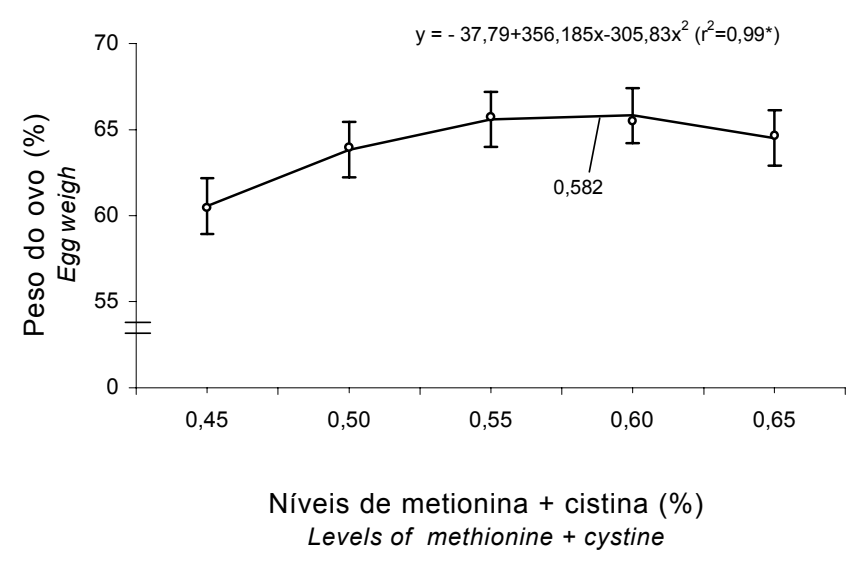

Figura 2 - Efeito dos níveis de metionina+cistina sobre o peso dos ovos.

Figure 2 - Effect of methionine+cystine levels on eggs weight. estudados neste trabalho. No entanto, a conversão alimentar expressa em gramas de ração por gramas de ovos produzidos sofreu influência dos tratamentos. A estimativa da exigência de met + cis determinada pelo modelo quadrático para a conversão alimentar em $\mathrm{g} / \mathrm{g}$ foi de $0,566 \%$ (Figura 4 ).

Maiores níveis de suplementação de met + cis nas rações favoreceram a melhor conversão, que pode ser resultante de um bom balanço de aminoácidos nas rações. Estes resultados estão condizentes com os encontrados por Rodrigues et al.(1996); Narváez Solarte (1996); e Barbosa (1997).

Com relação à variável ganho de peso corporal, não foram significativos $(\mathrm{P}>0,05)$ os efeitos dos níveis de met+cis nas rações.

$\mathrm{Na}$ avaliação da qualidade dos ovos provenientes de poedeiras de ovos marrons, alimentadas com diferentes níveis de suplementação de met+cis, verificou-se efeito quadrático $(\mathrm{P}<0,05)$ dos níveis crescentes de metionina+cistina nas rações sobre peso das cascas, percentagem de casca, altura do albúmen e Unidade Haugh (Tabela 5).

As características altura do albúmen e Unidades Haugh não foram afetadas pelos níveis de met + cis. Os resultados obtidos contrariam Rodrigues et al.(1996), que observaram melhora nos valores de Unidade Haugh dos ovos avaliados à medida que aumentavam os níveis de met+cis nas dietas. A exigência de met+cis para a Unidade Haugh foi estimada através da derivação do modelo quadrático em $0,558 \%$ (Figura 5).

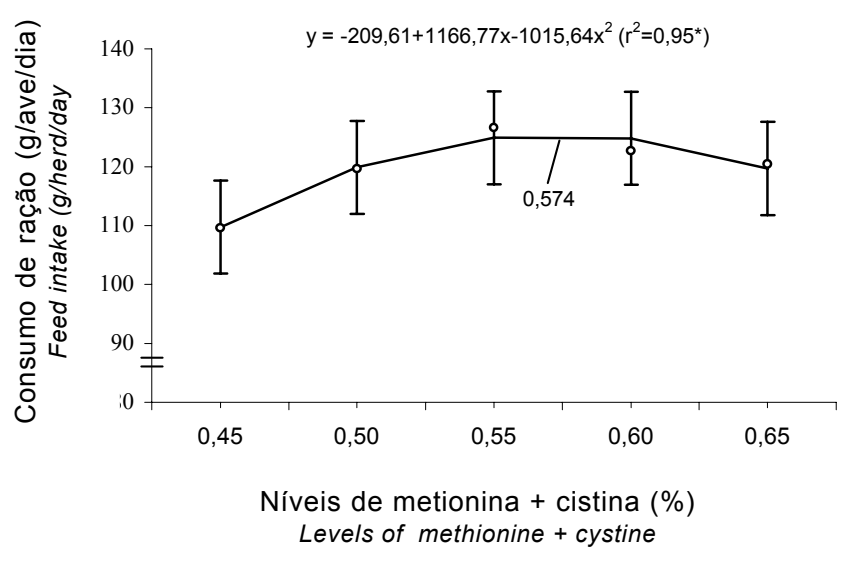

Figura 3 - Efeito dos níveis de metionina+cistina sobre o consumo de ração. * $(\mathrm{P}<0,05)$.

Figure 3 - Effect of methionine+cystine levels on feed intake. $*(P<.05)$

R. Bras. Zootec., v.31, n.3, p.1426-1433, 2002 (suplemento) 


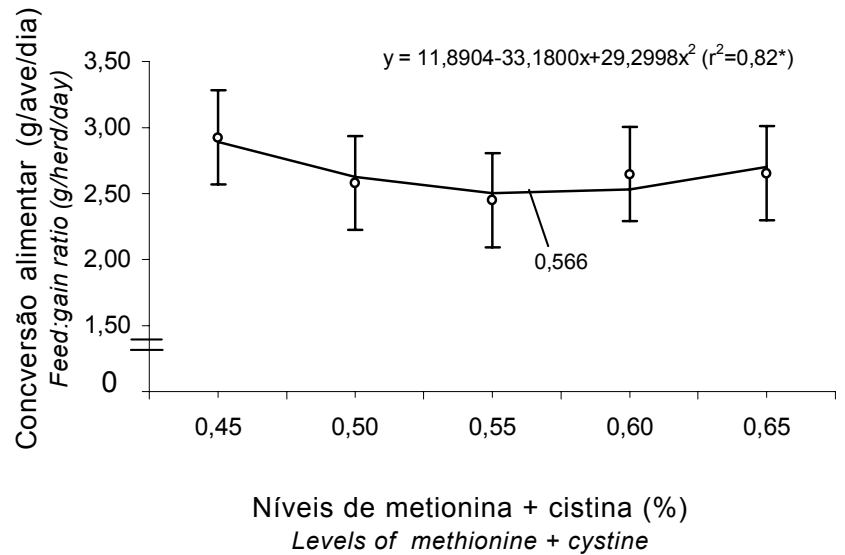

Figura 4 - Efeito dos níveis de met+cis sobre a conversão alimentar $(\mathrm{g} / \mathrm{g}) .{ }^{*}(\mathrm{P}<0,05)$.

Figure 4 - Effect of met+cys levels on Feed: gain ratio $(\mathrm{g} / \mathrm{g})$. ${ }^{*}(P<.05)$.

A gravidade específica e a percentagem de casca por superfície de área (PCSA) não foram afetadas significativamente $(\mathrm{P}>0,05)$ pelos níveis de met+cis. Não foi verificado nenhum efeito dos tratamentos sobre estas variáveis (Tabela 6), em concordância com os resultados obtidos por Rodrigues et al. (1996), que não encontraram diferenças na qualidade da casca do ovo quando ela foi avaliada pela PCSA. Entretanto, Roland (1980) e Petersen et al. (1983) obtiveram melhor qualidade da casca com a redução dos níveis de AAST. A qualidade da casca mensurada pela gravidade específica foi significativamente melhor.

Abdallah et al. (1993) concluíram que existem consideráveis correlações entre a percentagem de casca, a gravidade específica e a percentagem de

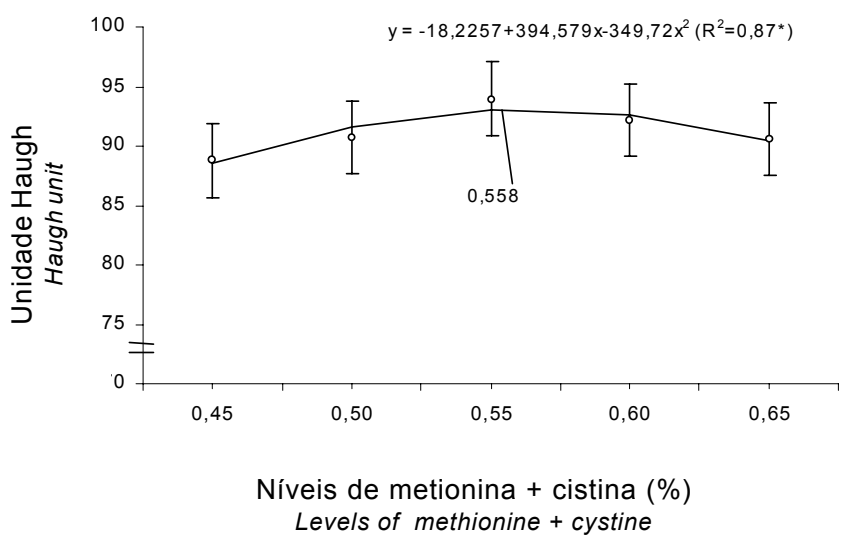

Figura 5 - Unidade Haugh em função dos níveis percentuais de met+cis na ração. * $(P<0.05)$.

Figure 5 - Effect of met+cys levels on Haugh Unit. ${ }^{*}(P<.05)$.

casca por superfície de área-PCSA com a percentagem de ovos quebrados. Neste trabalho, verificou-se alta correlação entre as variáveis quanto à qualidade da casca dos ovos. A correlação foi altamente positiva para as variáveis peso de casca e PCSA $(\mathrm{r}=0,96)$; Percentagem de casca e gravidade específica $(\mathrm{r}=0,79)$ e PCSA e peso das cascas $(\mathrm{r}=0,80)$.

Os dados de desempenho das aves são satisfatórios, tendo em vista a idade das aves, o baixo nível protéico e a utilização de levedura seca nas rações. O efeito quadrático dos níveis de met+cis nas rações sobre as variáveis analisadas está de acordo com resultados obtidos em trabalhos realizados anteriormente, confirmando os valores estimados das exigências de met+cis para as características de desempenho produtivo e qualidade de ovos.

Tabela 5 - Efeito dos níveis de met+cis sobre peso de casca, percentagem de casca, altura de albúmen e Unidades Haugh, de poedeiras de ovos marrons.

Table 5 - Effect of met+cys levels on shell weight shell percentage albumen high and Haugh Unit brown egg laying hens.

\begin{tabular}{lcccc}
\hline $\begin{array}{l}\text { Níveis de Met+cis (\%) } \\
\text { Met+cys levels }\end{array}$ & $\begin{array}{c}\text { Peso da casca (SW) } \\
(\mathrm{g})\end{array}$ & $\begin{array}{c}\text { Casca (SP) } \\
(\%)\end{array}$ & $\begin{array}{c}\text { Altura Albúmen (mm) } \\
\text { Albumen high }\end{array}$ & $\begin{array}{c}\text { Unidade Haugh } \\
\text { Haugh unit }\end{array}$ \\
\hline 0,45 & 6,61 & 10,94 & 7,56 & 88,79 \\
0,50 & 6,92 & 10,83 & 7,78 & 90,76 \\
0,55 & 6,92 & 10,53 & 8,31 & 93,98 \\
0,60 & 7,23 & 11,04 & 7,97 & 92,18 \\
0,65 & 6,90 & 10,68 & 7,69 & 90,55 \\
CV\% & 3,91 & 4,69 & 9,44 & 4,52 \\
\hline
\end{tabular}

Efeito quadrático significativo segundo o Teste $F(P<0,05)$.

Quadratic significant effect by test $F(P<.05)$.

R. Bras. Zootec., v.31, n.3, p.1426-1433, 2002 (suplemento) 
Tabela 6 - Efeito dos níveis de met+cis sobre a gravidade específica e percentagem de casca por superfície de área de poedeiras de ovos marrons

Table 6 - Effect of met+cys levels on especific gravity, shell weight per unit surface area (SWUSA) of brown egg laying hens

\begin{tabular}{lcc}
\hline $\begin{array}{l}\text { Níveis de Met+cis (\%) } \\
\text { Met }+ \text { cys levels }\end{array}$ & $\begin{array}{c}\text { Gravidade específica } \\
\text { Espefic gravity }\end{array}$ & $\begin{array}{c}\text { PCSA } \\
\left(\mathrm{mg} / \mathrm{cm}^{2}\right) \\
\text { SWUSA }\end{array}$ \\
\hline 0,45 & 1,0933 & 92,01 \\
0,50 & 1,0927 & 92,56 \\
0,55 & 1,0903 & 90,79 \\
0,60 & 1,0920 & 95,06 \\
0,65 & 1,0912 & 91,59 \\
CV\% & 0,22 & 4,25 \\
\hline
\end{tabular}

Não-significativo segundo teste Tuckey $(P>0,05)$ (Not significant effect by Tuckey Test $[P>$.05\}).

\section{Conclusões}

Os níveis de metionina+cistina recomendados para poedeiras de ovos marrons, visando à maximização das características referentes ao desempenho produtivo e à qualidade do ovo, foram, respectivamente, de 0,56 e 0,58 em rações à base de milho e farelo de soja contendo levedura seca.

\section{Literatura Citada}

ABDALLAH, G.A.; HARMS, R.H.; EL-HUSSEINY, O. Various Methods of measuring shell quality in relation to percentage of cracked eggs. Poultry Science, v.72, p.2038-2043, 1993.

BARBOSA, B.A.C. Exigências nutricionais em metionina+cistina e lisina para galinhas poedeiras leves e semi-pesadas, no segundo ciclo de produção. Viçosa, MG: Universidade Federal de Viçosa, 1997. 87p. Dissertação (Mestrado em Zootecnia) - Universidade Federal de Viçosa, 1997.

BOTELHO, F.G.A.; SERAFINI, F.V.; BUTOLO, E.A. Estudo do desempenho de galinhas poedeiras alimentadas com levedura de cana-de-açúcar (Saccharomyces cerevisiae). In: REUNIÃO ANUAL DA SOCIEDADE BRASILEIRA DE ZOOTECNIA, 35., 1998, Botucatu. Anais....Botucatu: Sociedade Brasileira de Zootecnia, 1998. p.324-326.

FILHO, J.I.S.; TALAMINI, D.J.D.; CHIUETTA, O. Panorama Avícola. Anuário 2000 da Avicultura Industrial, n.1074, Dez 99/Jan 00. p. 38-42.

HARMS, R.H.; DAMRON, B.L. Protein and sulfur amino acid requirement of the laying hen as influenced by dietary formulation. Poultry Science, v.48, n.1, p.144-149, 1969.

HARMS, R.H.; RUSSEL, G.B.; HARLOW, H. et al. The influence of methionine on commercial laying hens. Journal of Applied Poultry Research, v.7, p.45-52, 1998.

HARPER, A.E.; BENEVENGA, N.J.; WOHLHUETER, R.M. Effects of ingestion of disproportionate amounts of amino acids. Phisiological Reviews, v.50, n.3, p. 428-558, 1970.

HAUGH, R.R. The Haugh unit for measuring egg quality. U.S. Egg and Poultry Mag., v.43, p.552, 1937.

ISA Guía de Manejo Ponedoras Isabrown. Lyon: Institut de Sélection Animal, v.2, 12p. 1993.

JACKSON, M.E.; HELLWIG, H.M.; WALDROUP, P.W. Shell quality: potential for improvement by dietary means and relationship with egg size. Poultry Science, v.66, p.1702-1713, 1987.

JENSEN, S.L.; FALEN, L.; SCHUMAIER, W.G. Requirement of white Leghorn laying and breeding hens for methionine as influenced by stage of production cycle and inorganic sulfate. Poultry Science, v.53, p.535-544, 1974.

LANDEL FILHO, L.C.; KRONKA, R.N.N.; THOMAZ, M.C. et al. Utilização da levedura de centrifugação da vinhaça (Saccharomyces cerevisiae) como fonte protéica para leitões na fase inicial (10 a $30 \mathrm{~kg}$ PV). Revista da Sociedade Brasileira de Zootecnia, v.23, n.2, p.282-291, 1994.

LIMA, G.J.M.M.; LAVORENTI, A.; PACKER, I.U. et al. Uso da levedura seca de destilarias de álcool de cana-de-açúcar na alimentação de matrizes suínas em gestação e lactação. IIEfeitos sobre o peso dos leitões e das leitegadas. Revista Brasileira de Zootecnia, v.17, n.5, p.475-485, 1998.

MIYADA, V.S.; LAVORENTI, A. Uso da levedura seca (Saccharomyces cerevisiae) de destilarias de álcool de cana-de açúcar na alimentação de suínos em crescimento e acabamento. Revista Brasileira de Zootecnia, v.8, n.3, p.497-515, 1979.

MORENG, R.E.; AVENS, J.S. Ciência e produção de aves. São Paulo: Livraria Roca, 1990. 380p.

NARVÁEZ SOLARTE, W.V. Exigências em metionina + cistina para poedeiras leves e semipesadas. Viçosa, MG: Universidade Federal de Viçosa, 1996. 57p. Tese (Doutorado em Zootecnia) - Universidade Federal de Viçosa, 1996.

PANOBIANCO, M.A.; ARIKI, J., JUNQUEIRA, O.M. Utilização de levedura seca (Saccharomyces cerevisiae) de álcool de cana-de-açúcar em dietas de poedeiras. Revista da Sociedade Brasileira de Zootecnia, v. 18, n.1, p.13-20, 1989.

PEPPLER, H.J. Food yeast. In: ROSE, A.H.; HARRISON, J.S. (Eds.) The yeast. 2.ed. London: London Academic Press, v.3. 1970. p.421-462.

PETERSEN, C.F.; SAUTER, E.A.; STEELE, E.E. et al. Use of Methionine intake restriction to improve egg shell quality by control of egg weight. Poultry Science, v.62, p.2044-2047, 1983.

RODRIGUES, P.B.; BERTECHINI, A.G.; OLIVEIRA, B.L. et al. Fatores nutricionais que influenciam a qualidade do ovo no segundo ciclo de produção. I. Níveis de aminoácidos sulfurosos totais. Revista da Sociedade Brasileira de Zootecnia, v.25, n.2, p.248-260, 1996.

ROLAND, D.A. Egg shell quality. II. Effect of dietary manipulations of protein, amino acids, energy and calcium in young hens on egg weight, shell weight, shell quality and egg production. Poultry Science, v.59, p.2047-2054, 1980.

ROSTAGNO, H.S.; SILVA, D.J.; COSTA, P.M.A. et al. Composição de alimentos e exigências nutricionais de aves e suínos (Tabelas Brasileiras). Viçosa, MG: Universidade Federal de Viçosa, 1994. 61p.

SCHUTTE, J. B.; DE JONG, J.; BERTRAM, H. L. Requirement of the laying hen for sulfur amino acids. Poultry Science, v.73, p.274-280, 1994.

SEKIZ, S.S.; SCOTT, M.L.; NESHEIM, M.C. The effect of methionine deficiency on body weight, food and energy utilization in the chick. Poultry Science, v.54, p.11841188,1975 .

UNIVERSIDADE FEDERAL DE VIÇOSA- UFV. SAEG-Sistema para análise estatística e genética. Versão 7.1 Viçosa, MG. 150p. ( Manual do usuário). 1997.

WALDROUP, P.W.; HELLWIG, H.M. Methionine and Total Sulfur Amino Acid requirements influenced by stage of production. Journal of Applied Poultry Research, v.4, p.283-292, 1995.

R. Bras. Zootec., v.31, n.3, p.1426-1433, 2002 (suplemento)

Recebido em: 13/07/01 Aceito em: 01/04/02 